\title{
The Global Burden of Surgical Disease: An Analysis of Inaccessible Surgical Care in Low and Middle Income Countries
}

\section{Chau HUYNH* 1 , Minh N.Q. HUYNH ${ }^{1}$}

1 Student, University of Ottawa, Canada

*Auteur(e) correspondant | Corresponding author : chuyno97@uottawa.ca

\section{Résumé :}

(traduction)

\section{Mots-clés :}

À l'échelle mondiale, 4,8 milliards de personnes n'ont pas accès à des soins chirurgicaux ni à une gestion de l'anesthésie sécuritaires ou adéquats. Les soins chirurgicaux sont considérés comme « le parent pauvre de la santé mondiale »; un rappel frappant des disparités en matière de soins de santé. Les interventions chirurgicales peuvent prévenir 11 pour cent de la charge mondiale de morbidité et 1,5 million de morts annuellement. Cependant, de nombreux obstacles empêchent les pays à revenu faible et intermédiaire (PRFI) d'accéder à des soins chirurgicaux. Le premier défi consiste à offrir des soins chirurgicaux efficients malgré les restrictions financières et les bouleversements politiques. De l'aide étrangère a été mise en place pour alléger le fardeau financier et ses contributions ont été essentielles. Mais dans certains pays, en raison du climat politique, les fonds destinés au domaine de la santé sont détournés vers d'autres secteurs du gouvernement. De plus, le manque d'infrastructure, d'équipement et de personnel dans les PRFI aggrave la situation. Le second défi consiste à déterminer si une intervention chirurgicale est possible et aussi efficace qu'une intervention non chirurgicale. Les soins chirurgicaux sont essentiels et cet article vise à évaluer quels sont les obstacles qui limitent l'importance qu'on leur accorde dans les discussions portant sur la santé mondiale. Cet article abordera l'impact du financement, de l'infrastructure, de la main-d'œuvre, de la prestation de service et de la gestion de l'information sur les soins chirurgicaux, ainsi que les solutions actuelles telles que les missions d'aide humanitaire.

Services de santé, pays à revenu faible et intermédiaire, chirurgie 
Abstract:

Keywords:
Worldwide, 4.8 billion people do not have access to safe, adequate surgical care and anaesthetic management. Surgical care has been deemed "the neglected child of global health," a startling reminder of the disparities in health services. The provision of surgical interventions can avert $11 \%$ of the global burden of disease and 1.5 million deaths each year. Many obstacles exist for low- and middle-income countries (LMIC) to progress towards accessible surgical care. The first challenge is delivering cost-effective surgical care despite financial constraints and political turmoil. Foreign aid was established to alleviate the financial burden and its contributions have been pivotal. However, based on the political climate in certain countries, funds are siphoned to government sectors other than health care. Moreover, the lack of infrastructure, equipment, and personnel in LMIC compound the issue. The other challenge is determining if surgery is as feasible and effective as non-surgical health interventions. Surgical care is crucial and this paper aims to assess the challenges that limit its stature in global health discussions. The paper will address the influence of financing, infrastructure, workforce, service delivery, and information management on surgical care, and the current resolutions, such as humanitarian aid missions.

Health services, low- and middle-income countries, surgery 


\section{Introduction}

Worldwide, 4.8 billion people do not have access to safe, adequate surgical care and anaesthetic management (Myles \& Haller, 2010; Meara et al., 2015). Of the 248 million surgeries performed each year, $75 \%$ are performed in the wealthiest nations while the poorest countries only receive $4 \%$ of operations (Myles \& Haller, 2010). Low- and middleincome countries (LMIC) are facing a double burden of communicable and non-communicable diseases (Bygbjerg, 2012). Among the array of communicable and noncommunicable diseases, surgical interventions can treat acute etiologies such as infections, abscesses, and osteomyelitis or chronic diseases such as cataracts, malignancies, and congenital anomalies (WHO, 2011; Ologunde, Maruthappu, Shanmugarajah, \& Shalhoub, 2014). As these incidences continue to increase, the need for surgical care will be unprecedented.

The provision of surgery has been essential in advancing medical achievements and human health. In 2010, approximately $32.9 \%$ ( 16.9 million) of deaths worldwide were from conditions needing surgical care, surpassing the combined total of deaths from HIV/AIDS, tuberculosis, and malaria (Meara et al., 2015). As such, the global burden of disease (GBD) was established to assess risk factors, disease, and mortality using disability-adjusted life years (DALY) (WHO, 2011). Conditions requiring surgical interventions account for $11 \%$ of the treatable GBD (WHO, 2011; Fuller, 2017).

According to the third edition of the Disease Control Priorities (Debas et al., 2015), 1.5 million deaths and 77 million DALYs could be prevented each year if the 44 essential surgical procedures were provided. These surgeries can be identified in seven broad categories: dental, obstetric and gynecological, general surgery, injury, congenital, visual impairment, and non-trauma orthopaedic (Mock et al., 2015). This is a startling reminder of the disparities that continue to exist in health care in LMIC, yet surgical and anaesthetic care continue to be discounted from public discussion. Surgery is considered "the neglected stepchild of global health" (Farmer \& Kim, 2008) yet it remains one of the most crucial health services to an independent health care system.

First, this paper aims to address the financial and political challenges for surgical and anaesthetic care in LMIC. The specific contexts to these challenges are the impact of financial constraints, fiscal policies, and political turmoil on population health. Second, the paper will discuss the concerns regarding the cost-effectiveness of global surgical care. The remainder of the paper will discuss the benefits and limitations of current resolutions, such as humanitarian aid missions and micro-level projects.

\section{Discussion}

The delivery of cost-effective care is one of the many barriers to accessible surgical care for individuals living in LMIC. According to the World Bank Classification (2016), LMIC are defined as countries with a gross national income of less than $\$ 3,955$ per capita. Standard equipment, facility management, and training are necessary inputs to facilitate basic, accessible surgical care. However, the financial and political climate is not feasible to deliver accessible and affordable surgical care. This is not to argue that the government does not allow for accessible surgical care, but rather that surgical care is not recognized as a primary choice of intervention. During the "Millennium Development Goals" era, most of the significant political attention accosted to global health challenges led to the awareness and improvement of international donations. To build on the Millennium Development Goals, the Sustainable Development Goals (SDGs) for the 2030 Agenda were established and adopted by world leaders (UN, 2015). However, surgical and anaesthetic care was not incorporated as part of the 17 goals to alleviate poverty and achieve global health.

\section{Financing}

McIntyre et al. (2017) estimate that LMIC should allocate $5 \%$ of their total gross domestic product (GDP) for healthrelated spending to overcome resource deficiencies. This has been quantified in reference to the worldwide $5.5 \%$ average expenditure of GDP on health resources. However, the absolute monetary value of GDP varies greatly between countries. For instance, the GDP of the United States stands at $\$ 18.5$ trillion, whereas Burundi's is at $\$ 3$ billion (World Bank, 2016; BEA, 2015). Even if all LMIC reached the target goal of investing $5 \%$ of their GDP towards health care, no low-income countries and only $60 \%$ of middle-income countries would be able to provide basic universal health care coverage for essential medical services. It is rather difficult to define how much a country should invest into health expenditure as it depends on a number of factors, including per capita GDP, demographic trends in population, disease prevalence, and type of health system financing structure (Ke, Saksena, \& Holly, 2011). Most countries use out-of-pocket (OOP) payments as a form of financing for health services. In LMIC, 32.8 million individuals out of 150 million face catastrophic effects from OOP payments for surgical services per year (Chao et al., 2014). Catastrophic payments are the OOP spending that exceeds the household's income, leading individuals to suffer the burden of disease (WHO, 2012). If there is a $1 \%$ increase in health expenditure by OOP payments, a proportion of households will face a $2.2 \%$ increase in catastrophic payments (McIntyre, Meheus, \& Røttingen, 2017; Xu et al., 2003). 
Therefore, OOP is one of the factors that can significantly impact health care expenditure. Quantifying a recommended figure for all countries for health care expenditure is unreasonable, as it does not account for each country's unique needs.

It is clear that finances still remain a large barrier to LMIC. One innovative method of funding has been the financial assistance from foreign countries to LMIC nations for the purpose of improving health-related sectors, coined "Development Assistance for Health" (DAH). Since its introduction in 1990, DAH has been a major source of foreign funding for developing nations. In 2012, approximately $\$ 28$ billion was contributed by DAH, with the majority of finances directed towards communicable diseases such as HIV/ AIDS, malaria, tuberculosis, maternal and newborn health, and health research (Lu et al., 2010). It has allowed developing countries to make great strides in their health care development.

However, a criticism of DAH is the siphoning of government health service funds towards other domestic sources. Lu et al. (2010) examined the relationship between the allocation of government resources and DAH funding for health care resources. It was noted that in some countries instead of the DAH being used to supplement government funding, it was used to mitigate costs. In fact, it was found that on average, for every dollar received from DAH, the government reduced "expenditures allocated to the Ministry of Health and other government agencies that engage in health spending by $\$ 0.43$ to $\$ 1.14$ " (Lu et al., 2010). This stems from the conflicting objectives and hierarchy of the government. The Ministry of Finance controls the DAH budget that the Ministry of Health receives. In turn, the Ministry of Health has the primary directive of focusing resources to health care while the Ministry of Finance's purpose is to re-direct funding in the best interests of the country. Although health care is essential for the welfare of a country, other matters may take priority such as the economy or education. Furthermore, the Ministry of Finance has ultimate control over DAH funds and can re-direct the funds at their discretion. Therefore, a major criticism is that although there is a large organization supplementing developing countries' health care system, the money may not be accessible for this purpose due to barriers in the government structure.

\section{Infrastructure}

Given the financial state of developing countries, most hospital infrastructure is not equipped to deliver surgical care and can therefore have a negative impact on population health. In order to ensure safe surgical care, standardized equipment in operating rooms must be sterile and effective.
Most surgical equipment designed for hospitals is equipped with pressurized water, a boiler system, electricity, and pneumatic systems - conditions that are nonexistent in low -income countries (O’Hara, 2015; Grimes, Bowman, Dodgion, \& Lavy, 2011). Nearly $95 \%$ of LMIC hospitals receive equipment through donations, which are often missing necessary components, are difficult to repair, or are out of service (O'Hara, 2015). Furthermore, the average LMIC spends $\$ 6$ to $\$ 12$ per capita on medical equipment. This aligns with $90 \%$ of the world spending only $\$ 6$ per capita on medical equipment. In stark contrast, developed nations spend upwards of $\$ 290$ per capita on medical equipment (Nimunkar, Baran, Van Sickle, \& Webster, 2009). The cost of medical technology therefore serves as a consistent barrier.

Furthermore, essential medications and personal protective equipment are out-of-stock due to the lack of funds or management leading to disposable materials being reused. Most of the infrastructure in LMIC hospitals is unequipped to perform safe, surgical care. For example, out of 14 hospitals in Uganda, only four have a proper waste disposal incinerator, eight have access to oxygen (i.e., tanks, banks, infusers), and only one hospital has a working autoclave sterilization machine (Linden et al., 2012). Similarly in Afghanistan, one third of hospitals has no access to blood banks (Contini et al., 2010). Without the appropriate sanitary conditions and proper equipment, patients have a greater chance of acquiring surgical-site infections, pneumonia, urinary tract infections, blood-stream infections, or other health careassociated infections (Revelas, 2012). As a result of the financial climate, there are considerable disparities in hospital infrastructure and equipment that can put patients at an increased risk of mortality and morbidities.

\section{Work force, service delivery, and management}

Trained health care providers and health systems management are essential to the delivery of safe, accessible surgical care. In LMIC, there is a lack of health care managerial systems due to economic and political circumstances. Reducing financial gain can affect the incentives for surgical providers and medical personnel to improve quality of service and respond to patient demand in health care discussions (Chao et al., 2014). A stemming issue is the availability of trained physicians and anaesthesiologists. For instance, Rwanda has 50 surgeons for 11 million individuals and $\mathrm{Bu}-$ rundi has only 15 surgeons for ten million individuals (Henry et al., 2015).

Another common issue is the lack of medical expertise in LMIC. A study reported that patients are often referred to untrained medical attendants (Mullan \& Frehywot, 2007). The deficits in the workforce are based on a number of factors relating to the underfunding of health facilities, poor 
remuneration, poor retirement provision, lack of postgraduate training, and civil unrest (Pang, Lansang, \& Haines, 2002; Cometto, Tulenko, Muula, \& Krech, 2013). In some district hospitals in Mozambique, Tanzania, and Uganda, surgical and anaesthetic care is provided by medical attendants rather than trained physicians who do not have adequate knowledge and training to handle medical crises (Grimes et al., 2011; Henry et al., 2015). Another major burden on the health care system and educational system is the "brain drain" phenomenon, whereby medical professionals from developing countries migrate to developed nations. In Africa, almost 23,000 qualified academic professionals emigrate every year for better remuneration and working conditions (Pang et al., 2002). The global shortage of physicians and insufficient training for medical attendants poses a significant risk for potential patients in the deliverance of health services. Even more, for patients living in rural areas, surgical care becomes more difficult to access due to costs of transportation, rehabilitation fees, limited facilities, and medical professionals (Grimes et al., 2011). Overall, patient satisfaction, management, and accessible health services are dependent on the physician to population ratio, service providers with appropriate training and resources, and fair employment conditions.

\section{Cost-effectiveness}

The ultimate concern for policymakers in LMIC and abroad is whether surgical care is cost-effective. Several studies agree that implementing surgical care with other interventions is expensive and complex, but suggest that it is attainable. The DALY approach has been used to analyze the costeffectiveness of surgical care by comparing the monetary cost to avoid the loss of one year of healthy life (Chao et al., 2014; Ozgediz \& Riviello, 2008). In the assessment report of 112 surgical interventions, all surgical interventions costed less than $\$ 1000$ to avert a DALY. Some of these surgeries included cleft-lip repair, inguinal hernia repair, cataract surgery, and emergency caesarean section, all of which ranged from \$10-300 per DALY averted. By comparison, these are similar in cost to vitamin A supplementation, bed nets for malaria, HIV/AIDS antiretroviral therapy, and oral rehydration therapy (Meara et al., 2015; Alkire et al., 2011). Even more, Chao et al. (2014) posit that while medical missions might only focus on one type of surgical intervention, such as cleft palate repairs, it has the added benefit of increasing the capacity for all surgical services. This is due to the positive outcomes of such establishments and how these missions have led to widespread adoption in other countries (Marseille \& Morshed, 2014). The return-on-investments in surgical care can be greater than what is calculated at the individual level as these investments can lead to a global surgical spillover (Marseille \& Morshed, 2014). Hence, the cost of these surgical interventions is as favourable as or greater of an investment than other health-related interventions.

\section{Resolutions}

Apart from the DAH, the existing strategy for global surgical care is humanitarian relief missions providing support to areas with a high burden of disease. Organizations such as Operation Rainbow and Mercy Ships have been effective in providing surgical care. The success of their medical missions can be attributed to overcoming the scarcity of resources and budget costs and overcoming cultural and language barriers (Magee, Burg, \& Hatcher, 2010). The surgical outcomes of Operation Rainbow and Mercy Ships are comparable to high-income centers. Being equipped with their own laboratories, equipment, and resources allows the organizations to provide various procedures in eye care, reconstruction, general, orthopaedic, oral, and mental health, and palliative care (Magee, Burg, \& Hatcher, 2010).

For other organizations, medical missions can be hindered by financial and equipment constraints, language barriers, and the complexity of procedures (Shrime, Sleemi, \& Ravilla, 2014). For example, in several organizations, simple surgeries such as tonsillectomies have very low complication rates whereas other surgeries, such as hernias and cleft lip repair, have much higher complication rates. Hernia operations in Sub-Saharan Africa from medical missions have a mortality rate of $1 \%$, which is 20 times greater than in higher income countries.

Despite the number of surgical organizations, evaluating the effectiveness of global surgical care still remains an issue due to the lack of patient follow-up care and failure to implement a focused short-term approach (Shrime et al., 2014). In addition, while humanitarian outreach has provided medical advantages, it focuses on specialty care for injuries and warfare, leaving a large gap in care for congenital and acquired deformities (Malay, 2017). In the broader scheme, challenges to humanitarian action are the loss to follow-up, high volume of patients, resource shortages, limited support services from local authorities, and paucity of preventative care (Chiu, Weng, Chen, Yank, \& Lee, 2014). Given the global humanitarian efforts to overcome the global burden of disease, there remain obstacles in providing adequate and effective surgical care.

\section{Recommendations}

From a holistic perspective, inaccessible surgical care is a multifaceted social, economic, and political issue, but global surgical care can be achieved. Compiling several studies, the current literature suggests focusing on five key factors: in- 
frastructure, workforce, service delivery, financing, and information management (Meara et al., 2015; O’Hara, 2015; Henry et al., 2015). Tackling the challenges associated with inaccessible surgical care is imperative to move forward. The broad recommendations for LMIC include: enhancing managerial systems, providing training and education, incorporating rural support, providing telemedicine, identifying and allocating research priorities, and creating a national budget for health care. While these are major recommendations which cannot be implemented in a short time span, they are a starting point for local and foreign policymakers. From a community perspective, certain projects aspire to resolve the "minor" issues for citizens and health care providers. For example, the REMEDY (Recovered Medical Equipment for the Developing World) project works to promote the recovery of unused medical supplies and its costeffectiveness. In contrast to unsalvageable donations, these donations are unused and can range from gloves and syringes, to operable ambulances and $\mathrm{x}$-ray machines. To address the current issues, REMEDY works to alleviate the limitations in resources, transportation, rehabilitation, and other expenses.

\section{Conclusion}

Surgical care is an essential service that is required to achieve a comprehensive health care system. Despite its importance in achieving equitable health, considerable disparities in access to surgical services remain. The Sustainable Development Goals for 2030 are an example of how, despite their documented health benefits, surgical services are not prioritized. Although there is an urgent need to address the implementation of surgical services, there are financial and political obstacles that have made it difficult to actualize. The impacts of these challenges have cumulated into the current state of affairs regarding medical equipment, infrastructure, and trained service providers. As a consequence, populations in LMIC have a greater risk for injuries, morbidities, and mortalities. Regardless, the successes and shortcomings of humanitarian aid missions and DAH were explored and both have contributed towards progressing universal surgical care. With strategic recommendations and awareness of the issues, the provision of essential surgical care can make great strides in overcoming the global burden of surgical disease.

\section{References}

Alkire, B., Hughes, C. D., Nash, K., Vincent, J. R., \& Meara, J. G. (2011). Potential economic benefit of cleft lip and palate repair in sub-Saharan Africa. World Journal of Surgery, 35(6), 1194-1201. doi:10.1007/so0268-011-1055-1
Bureau of Economic Analysis. (2015). Gross Domestic Product (GDP) by State. Washington, DC: United States Department of Commerce.

Bygbjerg, I. C. (2012). Double burden of noncommunicable and infectious diseases in developing countries. Science, 337(6101), 1499-1501. doi:10.1126/ science.1223466

Chao, T. E., Sharma, K., Mandigo, M., Hagander, L., Resch, S. C., Weiser, T. G., \& Meara, J. G. (2014). Cost-

effectiveness of surgery and its policy implications for global health: a systematic review and analysis. The Lancet Global Health, 2(6), 334-345. doi:10.1016/S2214-109X(14)70213-X

Chiu, Y. W., Weng, Y. H., Chen, C. F., Yang, C. Y., \& Lee, M. L. (2014). Perceptions and efficiency of short-term medical aid missions among key groups of health professionals. Evaluation \& the Health Professions, 37(3), 379-393. doi:10.1177/0163278712461503

Cometto, G., Tulenko, K., Muula, A. S., \& Krech, R. (2013). Health workforce brain drain: from denouncing the challenge to solving the problem. PLoS Medicine, 1O(9), 1001514. doi: 10.1371/journal.pmed.1001514

Contini, S., Taqdeer, A., Cherian, M., Shokohmand, A. S., Gosselin, R., Graaff, P., \& Noel, L. (2010). Emergency and essential surgical services in Afghanistan: still a missing challenge. World Journal of Surgery, 34(3), 473-479. doi: 10.1007/s00268-010-0406-7

Debas, H. T., Donkor, P., Gawande, A., Jamison, D. T., Kruk, M. E., Mock, C. N. (Eds.). (2015). Essential Surgery: Disease Control Priorities(3rd ed.). Washington, DC: World Bank.

Farmer, P. E., \& Kim, J. Y. (2008). Surgery and global health: a view from beyond the OR. World Journal of Surgery, 32(4), 533-536. doi:10.1007/s00268-008-9525-9

Fuller, J. C. (2017). Global surgery: current evidence for improving surgical care. Current Opinion in Otolaryngology \& Head and Neck Surgery, 25(4), 300-306. doi:10.1097/ MOO.0000000000000374

Grimes, C. E., Bowman, K. G., Dodgion, C. M., \& Lavy, C. B. (2011). Systematic review of barriers to surgical care in lowincome and middle-income countries. World Journal of Surgery, 35(5), 941-950. doi:10.1007/s00268-011-1010-1

Henry, J. A., Bem, C., Grimes, C., Borgstein, E., Mkandawire, N., Thomas, W. E., ... \& Cotton, M. H. (2015). Essential surgery: the way forward. World Journal of Surgery, 39(4), 822-832. doi:10.1007/soo268-014-2937-9 
Ke, X., Saksena, P., \& Holly, A. (2011). The determinants of health expenditure: a country-level panel data analysis. Geneva: World Health Organization.

Linden, A. F., Sekidde, F. S., Galukande, M., Knowlton, L. M., Chackungal, S., \& McQueen, K. K. (2012). Challenges of surgery in developing countries: a survey of surgical and anesthesia capacity in Uganda's public hospitals. World Journal of Surgery, 36(5), 1056-1065. doi:10.1007/s00268012-1482-7

Lu, C., Schneider, M. T., Gubbins, P., Leach-Kemon, K., Jamison, D., \& Murray, C. J. (2010). Public financing of health in developing countries: a cross-national systematic analysis. The Lancet, 375(9723), 1375-1387. doi:10.1016/ So140-6736(10)60233-4

Magee, W. P., Vander Burg, R., \& Hatcher, K. W. (2010). Cleft lip and palate as a cost-effective health care treatment in the developing world. World Journal of Surgery, 34(3), 420-427. doi:10.1007/s00268-009-0333-7

Malay, P. B. (2017). Short-Term Medical Missions and Global Health. The Journal of Foot and Ankle Surgery, 56 (2), 220-222. doi:10.1053/j.jfas.2017.01.031

Marseille, E., \& Morshed, S. (2014). Essential surgery is cost effective in resource-poor countries. The Lancet Global Health, 2(6), 302-303. doi:10.1016/S2214-109X(14)70236o

Mcintyre, D., Meheus, F., \& Røttingen, J. A. (2017). What level of domestic government health expenditure should we aspire to for universal health coverage?. Health Economics, Policy and Law, 12(2), 125-137. doi:10.1017/

S1744133116000414

Meara, J. G., Leather, A. J., Hagander, L., Alkire, B. C., Alonso, N., Ameh, E. A., ... \& Mérisier, E. D. (2015). Global Surgery 2030: evidence and solutions for achieving health, welfare, and economic development. The Lancet, 386 (9993), 569-624. doi:10.1016/j.ijoa.2015.09.006

Mock, C. N., Donkor, P., Gawande, A., Jamison, D. T., Kruk, M. E., \& Debas, H. T. (2015). Essential surgery: Key messages from disease control priorities, 3 rd edition. The Lancet, 385(9983), 2209-2219. doi:10.1016/So140-6736(15) 60091-5

Mullan, F., \& Frehywot, S. (2007). Non-physician clinicians in 47 sub-Saharan African countries. The Lancet, 370 (9605), 2158-2163.

Myles, P. S., \& Haller, G. (2010). Global distribution of access to surgical services. The Lancet, 376(9746), 1027-1028.
doi:10.1016/So140-6736(10)60520-X

Nimunkar, A. J., Baran, J., Van Sickle, D., \& Webster, J. G. (2009). Low-cost medical devices for developing countries. Proc. of 31st Annual International IEEE EMBC 2009.

O'Hara, N. N. (2015). Is safe surgery possible when resources are scarce?. BMJ Quality \& Safety, 24,432-434. doi:10.1136/bmjqs-2015-004377

Ologunde, R., Maruthappu, M., Shanmugarajah, K., \& Shalhoub, J. (2014). Surgical care in low and middle-income countries: Burden and barriers. International Journal of Surgery, 12(8), 858-863. doi: 10.1016/j.ijsu.2014.07.009

Ozgediz, D., \& Riviello, R. (2008). The "other" neglected diseases in global public health: surgical conditions in subSaharan Africa. PLoS medicine, 5(6), 121. doi:10.1371/ journal.pmed.0050121

Pang, T., Lansang, M. A., \& Haines, A. (2002). Brain drain and health professionals: a global problem needs global solutions. BMJ: British Medical Journal, 324(7336), 499.

Revelas, A. (2012). Healthcare-associated infections: A public health problem. Nigerian Medical Journal: Journal of the Nigeria Medical Association, 53(2), 59. doi:

10.4103/0300-1652.103543

Shrime, M. G., Sleemi, A., \& Ravilla, T. D. (2015). Charitable platforms in global surgery: a systematic review of their effectiveness, cost-effectiveness, sustainability, and role training. World Journal of Surgery, 39(1), 10-20. doi:10.1007/ soo268-014-2516-o

United Nations. (2015). Sustainable Development Agenda. Retrieved from http://www.un.org/ sustainabledevelopment/development-agenda/

World Health Organization. (2011). Metrics: DisabilityAdjusted Life Year (DALY). Retrieved from http:// www.who.int/healthinfo/global_burden_disease/ metrics_daly/en/

World Health Organization. (2012). Factors affecting catastrophic health expenditure and impoverishment from medical expenses in China: policy implications of universal health insurance. Retrieved from http://www.who.int/ bulletin/volumes/90/9/12-102178/en/

World Bank. (2016). International Monetary Fund: Burundi. Retrieved from http://databank.worldbank.org/data/ reports.aspx? source $=2 \&$ series $=$ NY.GDP.MKTP.CD\&country $=$ 
World Bank Classification. (2016). New Country Classifica-

tions by Income Level. Retrieved from https://

blogs.worldbank.org/opendata/new-country-classifications $-2016$

Xu, K., Evans, D. B., Kawabata, K., Zeramdini, R., Klavus, J., \& Murray, C. J. L. (2003). Household catastrophic health expenditure: a multicountry analysis. The Lancet, 362

(9378),111-117. 